\title{
Design and Optimization of the Geometric Properties of a Crane Hook
}

\author{
Niranjan Desai, Nuri Zeytinoglu \\ Department of Mechanical and Civil Engineering, Purdue University Northwest, Westville, IN, USA \\ Email: desai39@pnw.edu, nz@pnw.edu
}

Received 9 June 2016; accepted 31 July 2016; published 3 August 2016

Copyright (C) 2016 by authors and Scientific Research Publishing Inc.

This work is licensed under the Creative Commons Attribution International License (CC BY). http://creativecommons.org/licenses/by/4.0/

(c) (i) Open Access

\begin{abstract}
Cranes are used in many industries to transport heavy loads from one position to another. These loads are fastened to a crane hook which makes it a critical aspect of the crane itself. The purpose of this study is to optimize the performance of the crane hook based on stress, geometry, and weight. A single load is considered and multiple cross sections-including square, circular, and trapezoidal-are analyzed. The analysis takes the form of theoretical calculations and finite element analysis through the use of SOLIDWORKS Simulation. The trapezoidal cross section is determined to be the most efficient and the weight and stress of this cross section are optimized by varying the cross sectional parameters.
\end{abstract}

\section{Keywords}

\section{Crane-Hook, Geometric Properties}

\section{Introduction}

The stress and deflection in the crane hooks for this study are determined both using theoretical calculations as well as finite element analysis simulation in SOLIDWORKS. The theoretical calculations are based on Figure 1 shown below. It is possible to calculate the eccentricity $(e)$ and normal stress $(\sigma)$ in a curved hook based on Equation (1) and Equation (2), respectively. The neutral radius $\left(r_{n}\right)$ and eccentricity are determined based on the different cross sections shown in Figure 2. Square, trapezoidal, and circular cross sections are considered in this study [1].

$$
\begin{aligned}
& e=r_{c}-r_{n} \\
& \sigma=\frac{M y}{A e\left(r_{n}-y\right)}
\end{aligned}
$$



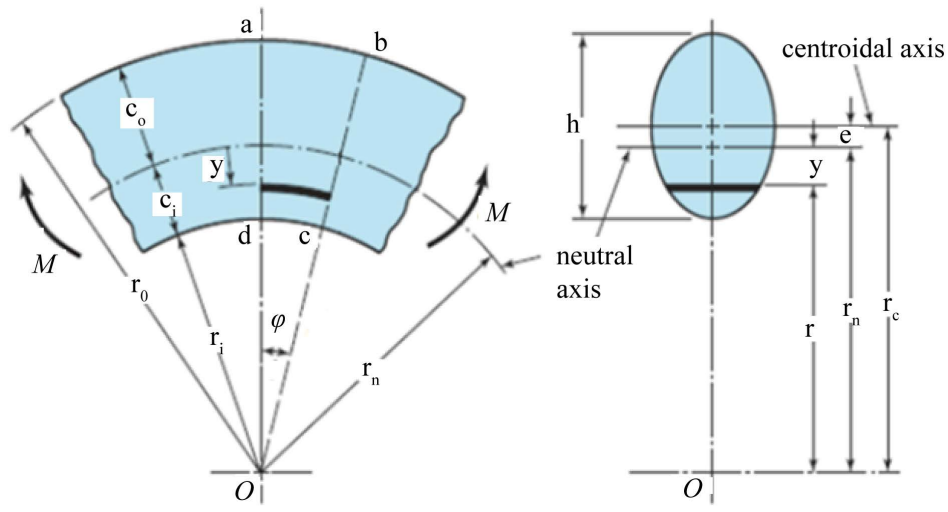

Figure 1. Parameters of a curved hook for stress calculations.
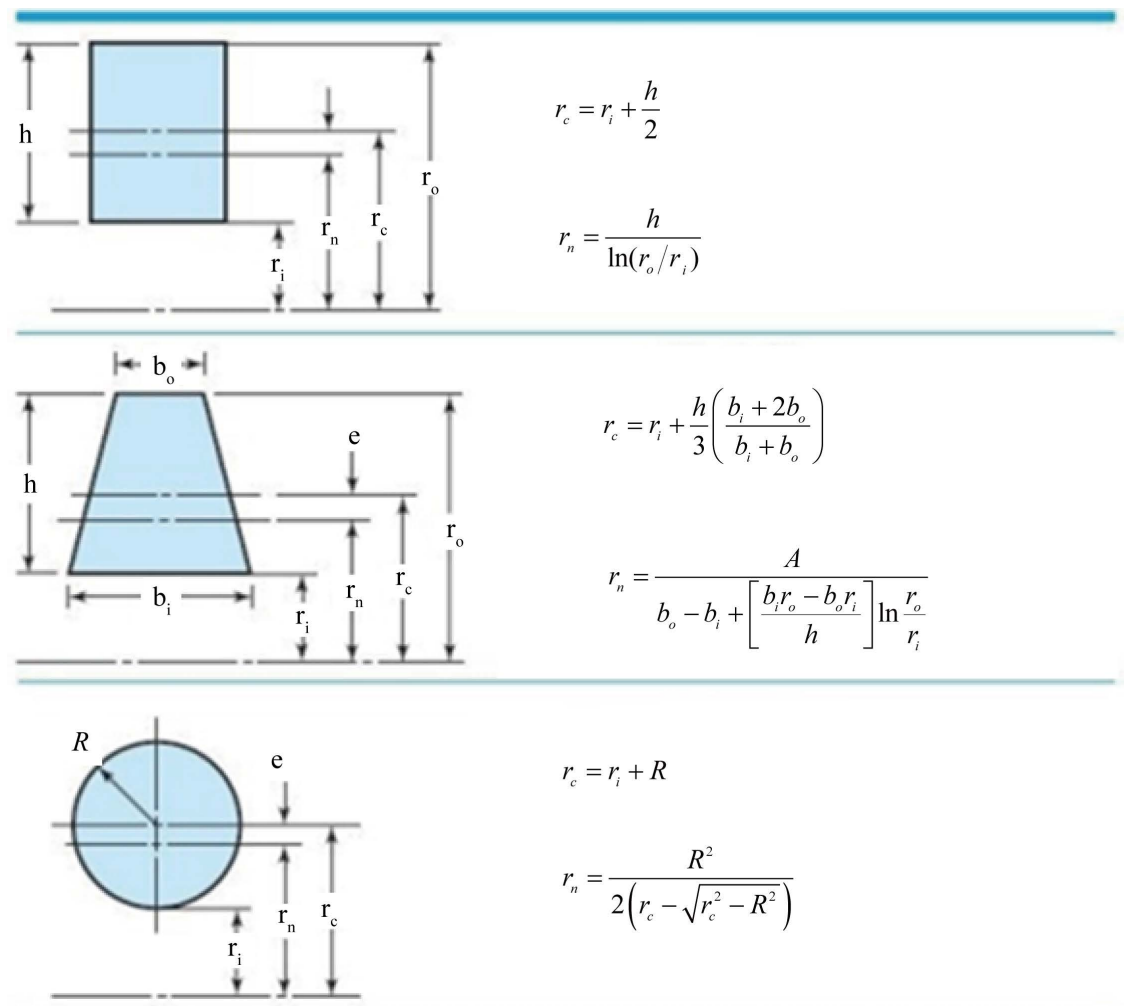

$r_{c}=r_{i}+R$

$r_{n}=\frac{R^{2}}{2\left(r_{c}-\sqrt{r_{c}^{2}-R^{2}}\right)}$

Figure 2. Diagrams and equations for determining the neutral axis and central radius for various cross sections.

\section{Results}

\subsection{Cross Section Selection}

The concept of loading a curved beam is used to determine the maximum stress and displacement in multiple cross section shapes including square, circular, and trapezoidal. A common cross sectional area and hook radius are used for all geometric selections and each cross sections centroid lies on the radius of curvature. The cross sections along with the parameters used for testing are shown in Figure 3.

These three cross sections are used to create solid models of a hook that has a radius of curvature of 4 in. The resulting solid models are used to perform finite element analysis in SOLIDWORKS. In this finite element analysis, a load of $8000 \mathrm{lbs}$ is considered and the resulting normal stress and deflection are analyzed. The finite element models shown in Figures 4-6 indicate the location of maximum stress, and Figures 7-9 show the de- 


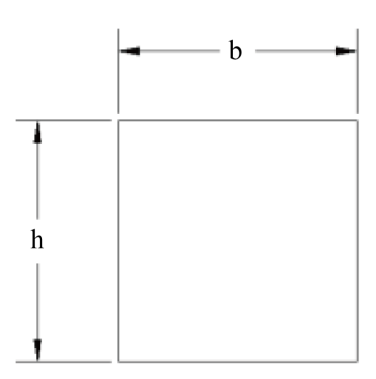

$\mathrm{b}=\mathrm{h}=2.12 \mathrm{in}$ $\mathrm{A}=4.5 \mathrm{in}^{2}$

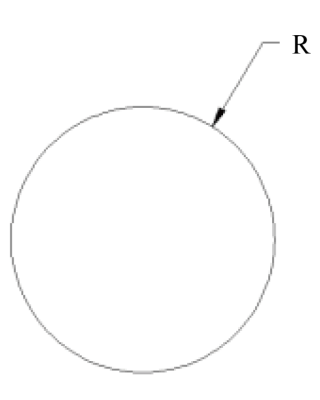

$\mathrm{R}=1.20 \mathrm{in}$ $\mathrm{A}=4.5 \mathrm{in}^{2}$

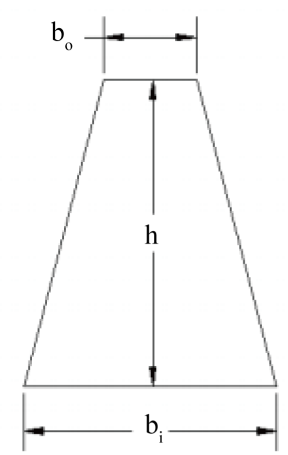

$\mathrm{h}=2.83$ in $\quad \begin{aligned} \mathrm{b}_{\mathrm{i}} & =2.33 \text { in } \quad \mathrm{b}_{\mathrm{o}}=0.85 \mathrm{in} \\ \mathrm{A} & =4 . \sin ^{2}\end{aligned}$

Figure 3. Square, circular and trapezoid cross sections and parameters used.

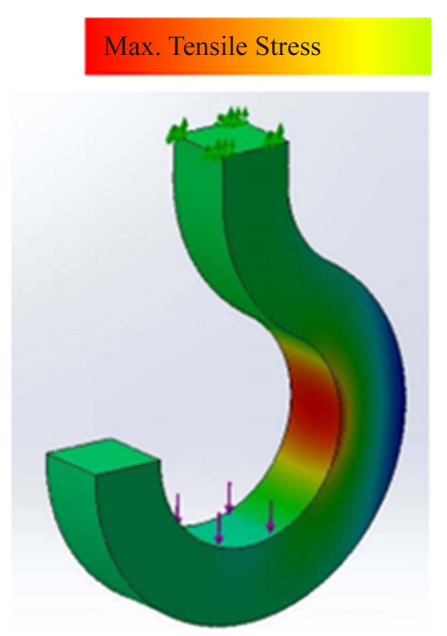

Figure 4. Square cross section normal stress plot.

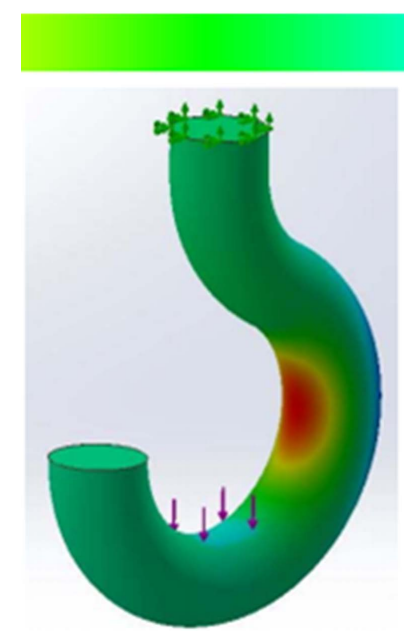

Figure 5. Circular cross section normal stress plot.

flection. These results are summarized in Table 1 . These results show that the trapezoid cross section has the most desirable performance due to the lower levels of stress and deflection in comparison to the square and circular cross sections [2]. 


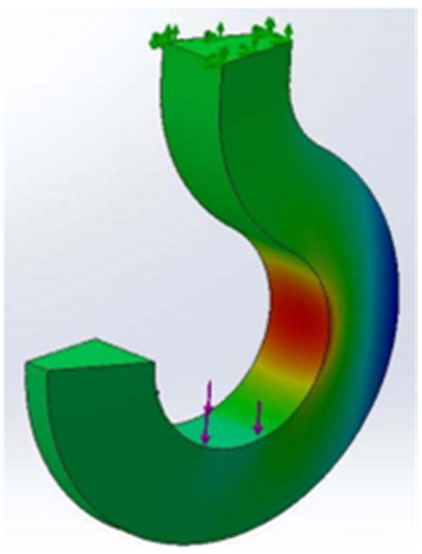

Figure 6. Trapezoid cross section normal stress plot.

Max. Positive Y-Deflection

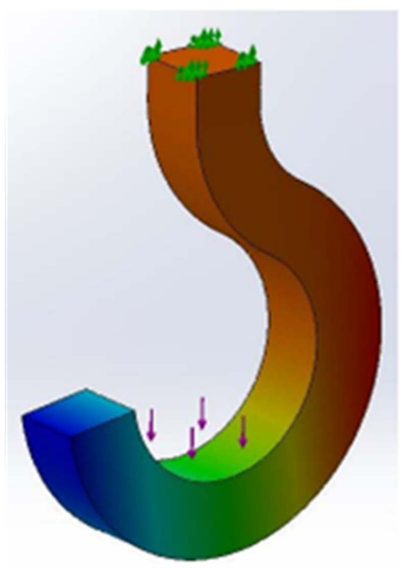

Figure 7. Square cross section y deflection plot.

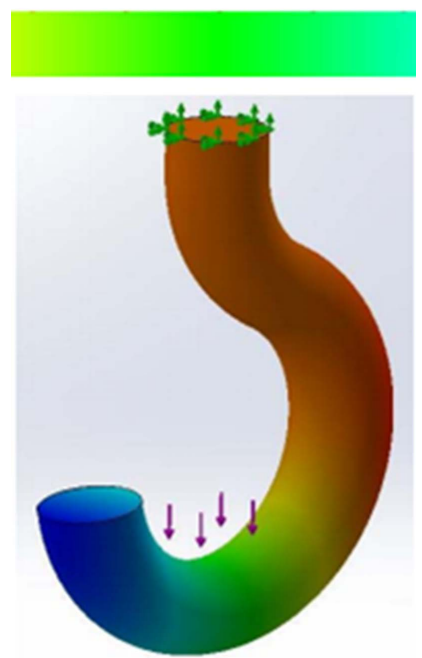

Figure 8. Circular cross section y deflection plot. 


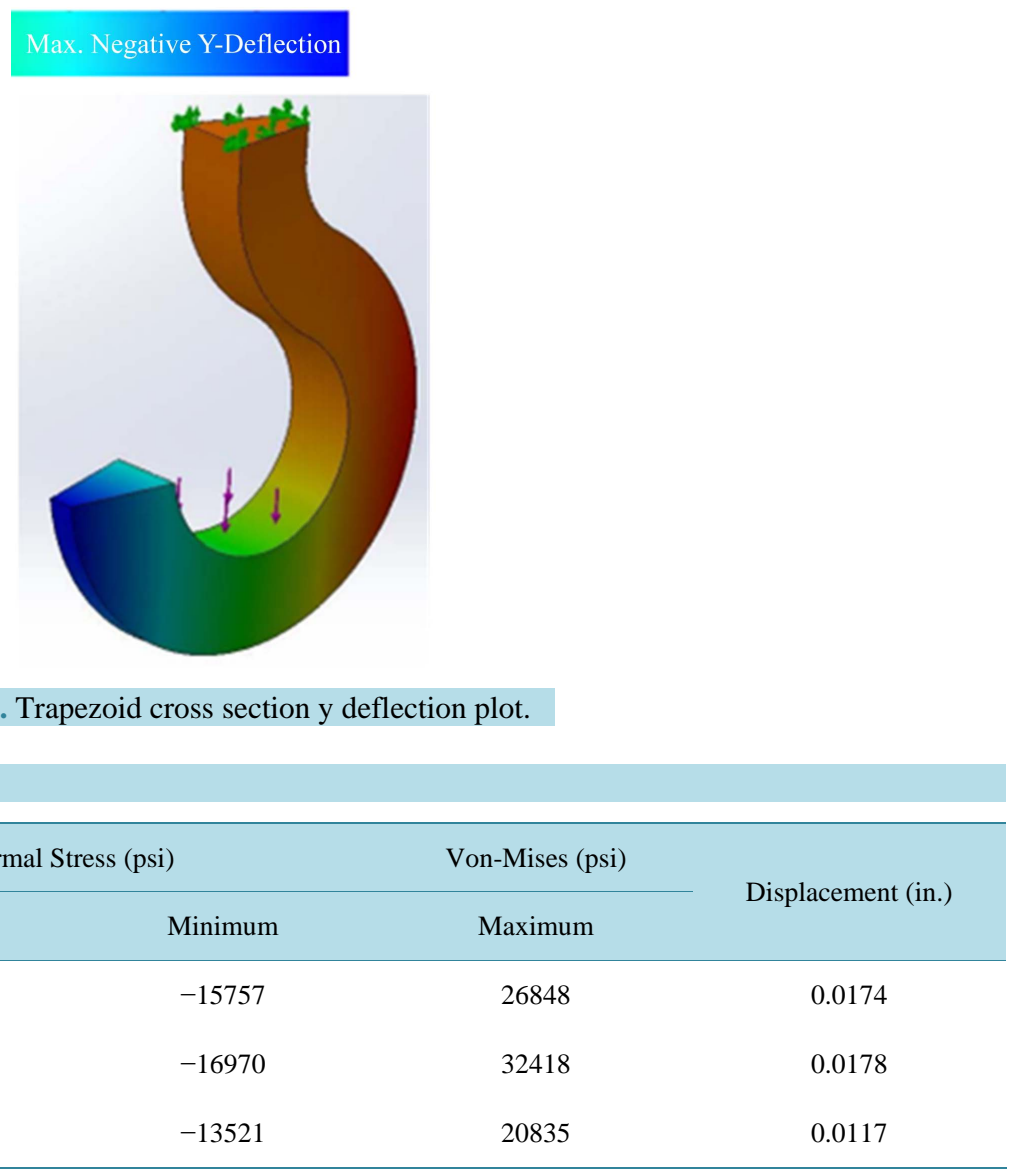

\subsection{Cross Section Optimization}

It is possible to determine the optimal geometric properties with the trapezoidal cross section selected. The parameters of the trapezoidal cross section detail in Figure 3 are varied to determine the values that provide the optimal performance. In order to achieve this, the value of the neutral radius $\left(r_{n}\right)$ is held constant at 3.5 in, while the values of $h, b_{i}$, and $b_{o}$ are varied simultaneously. The materials being considered in this optimization are A-36 steel, 6061-T6 Aluminum, and Ti-6AL-4V Titanium and their properties are shown in Table 2 [3]-[5]. By selecting 7 values of the parameter $h$, it is possible to determine values of $b_{i}$, and $b_{o}$ such that the weight is minimized and the maximum normal stress is constrained to one half of the materials yield strength $\left(\sigma_{y}\right)$. The results of this optimization are shown in Figure 10. Exact parameter values are shown in Tables A1-A3 in Appendix A [6] [7].

\section{Conclusions}

The results of this research show that for a given cross sectional area, a trapezoid cross section of a hook will have better performance in terms of maximum stress than a circular or square cross section. It is also shown that as the $h$ value of a trapezoidal hook increases, the minimum weight of the hook decreases at a decreasing rate. While the highest value for $h$ will give the lowest weight overall, it is important to keep the proportions of the hook in mind when making the parameter selection. A very large value of $h$ will increase the overall extents of the hook profile and create inefficiencies in packaging and will require a much larger opening on the load that is being moved.

Another observation that is made is in the difference in weight between the three materials while achieving the same goal of maintaining stress levels of one half of the materials yield strength. The percent decrease in weight between steel vs. aluminum or titanium can be as large as $80 \%$. This indicates that in terms of performance, aluminum or titanium will be a clear choice over steel. The difference between aluminum and titanium 
Table 2. Material properties.

\begin{tabular}{cccccc}
\hline Material & $\begin{array}{c}\text { Ultimate Tensile } \\
\text { Strength, } \mathrm{N} / \mathrm{mm}^{2}\left(\sigma_{u}\right)\end{array}$ & $\begin{array}{c}\text { Tensile Yield Strength, Modulus of Elasticity, } \\
\mathrm{N} / \mathrm{mm}^{2}\left(\sigma_{y}\right)\end{array}$ & Poisson's Ratio $(v)$ & Density $\mathrm{kg} / \mathrm{mm}^{2}(\rho)$ \\
\hline A-36 Steel & $400-550.2$ & 250.3 & 199948 & 0.26 & 7861 \\
6061-T6 Aluminum & 310.3 & 275.8 & 68947.6 & 0.33 & 2713 \\
Ti-6AL-4V Titanium & 951.5 & 882.5 & 113763.5 & 0.34 & 4429 \\
\hline
\end{tabular}

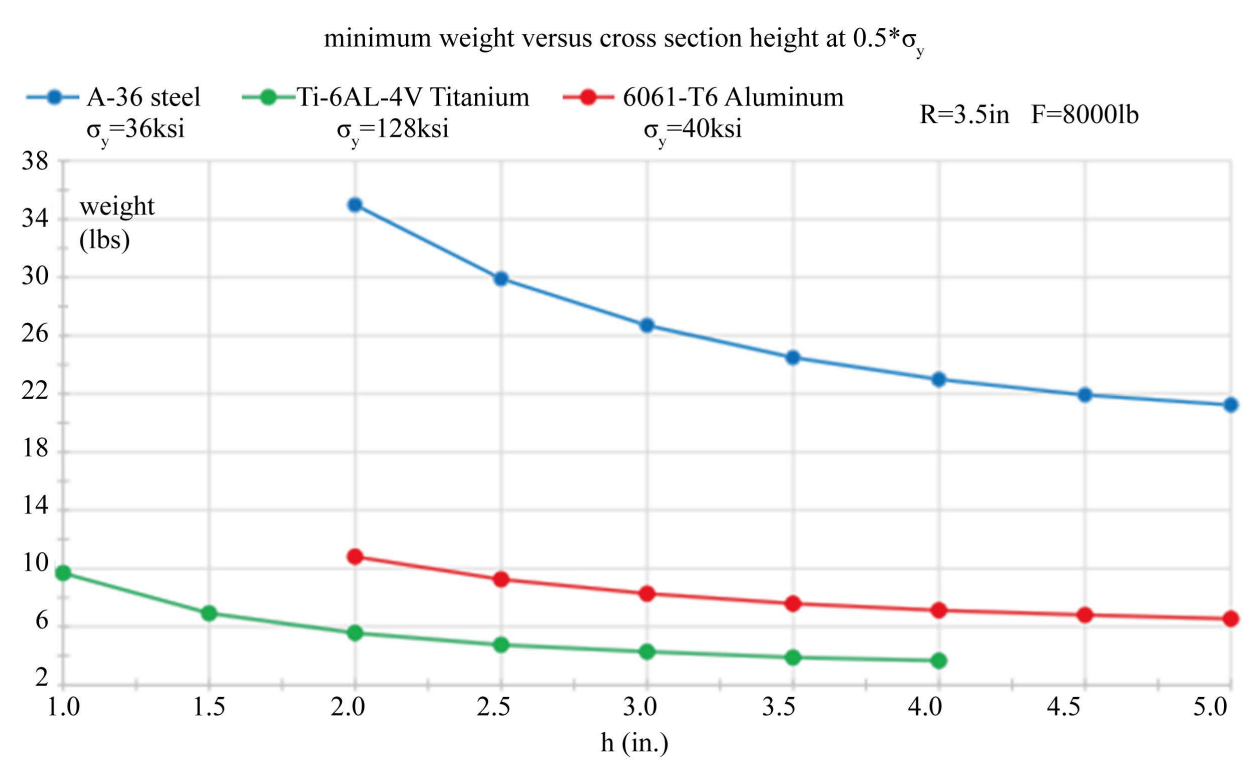

Figure 10. Weight optimization results for three different materials.

however is much smaller. This is where the cost of raw materials and the machinability of the material will factor heavily into the material selection decision.

\section{References}

[1] Budynas, R.G. and Nisbett, J.K. (2015) Mechanical Engineering Design. McGraw-Hill, New York.

[2] Sahu, G.N. and Yadav, N. (2013) Design and Stress Analysis of Various Cross Section of Hook. International Journal of Modern Engineering Research, 3, 2187-2189.

[3] MatWeb. (n.d.) Aluminum 6061-T6; 6061-T651.

http://www.matweb.com/search/datasheet.aspx?matguid=1b8c06d0ca7c456694c7777d9e10be5b

[4] MatWeb. (n.d.) ASTM A36 Steel, Bar.

http://www.matweb.com/search/datasheet.aspx?matguid=d1844977c5c8440cb9a3a967f8909c3a

[5] MatWeb. (n.d.) Ti-6Al-4V (Grade 5), Annealed. http://asm.matweb.com/search/SpecificMaterial.asp?bassnum=MTP641

[6] Patel, R.B., Pate, B.K., Pate, P.M., Patel, D.H. and Patel, H.S. (N/A) Design and Analysis of Crane Hook with Different Material. International Journal of Advanced Computer Technology, 4, 89-93.

[7] Bergaley, A. and Purohit, A. (2013) Structural Analysis of Crane Hook Using Finite Element Method. International Journal of Science and Modern Engineering, 1, 3-7. 
Appendix A

Optimized Cross Section Values

Table A1. Ti-6AL-4V titanium optimization.

\begin{tabular}{cccccc}
\hline$R(\mathrm{~mm})$ & $h(\mathrm{~mm})$ & $b_{\mathrm{i}}(\mathrm{mm})$ & $b_{0}(\mathrm{~mm})$ & Stress $\left(\mathrm{N} / \mathrm{mm}^{2}\right)$ & Weight $(\mathrm{kg})$ \\
\hline 88.9 & 25.4 & 109.2 & 30.48 & 440.6 & 4.391 \\
88.9 & 38.1 & 52.32 & 14.22 & 440.3 & 3.134 \\
88.9 & 50.8 & 32 & 8.128 & 439.4 & 2.522 \\
88.9 & 63.5 & 22.1 & 5.33 & 440.1 & 2.155 \\
88.9 & 76.2 & 16.76 & 3.81 & 436 & 1.941 \\
88.9 & 88.9 & 13.46 & 2.54 & 440.9 & 1.76 \\
88.9 & 101.6 & 11.18 & 2.032 & 438.3 & \\
\hline
\end{tabular}

Table A2. A36 steel optimization.

\begin{tabular}{|c|c|c|c|c|c|}
\hline$R(\mathrm{~mm})$ & $h(\mathrm{~mm})$ & $b_{i}(\mathrm{~mm})$ & $b_{0}(\mathrm{~mm})$ & Stress $\left(\mathrm{N} / \mathrm{mm}^{2}\right)$ & Weight (kg) \\
\hline 88.9 & 50.8 & 113 & 29.21 & 124 & 15.86 \\
\hline 88.9 & 63.5 & 78.23 & 19.05 & 124.1 & 13.56 \\
\hline 88.9 & 76.2 & 59.18 & 13.21 & 123.9 & 12.11 \\
\hline 88.9 & 88.9 & 47.5 & 9.4 & 124 & 11.1 \\
\hline 88.9 & 101.6 & 39.88 & 6.86 & 123.9 & 10.42 \\
\hline 88.9 & 114.3 & 34.8 & 4.826 & 123.9 & 9.943 \\
\hline 88.9 & 127 & 31.24 & 3.302 & 123.7 & 9.63 \\
\hline
\end{tabular}

Table A3. 6061-T6 aluminum optimization.

\begin{tabular}{|c|c|c|c|c|c|}
\hline$R(\mathrm{~mm})$ & $h(\mathrm{~mm})$ & $b_{i}(\mathrm{~mm})$ & $b_{0}(\mathrm{~mm})$ & Stress $\left(\mathrm{N} / \mathrm{mm}^{2}\right)$ & Weight (kg) \\
\hline 88.9 & 50.8 & 101.9 & 26.16 & 137.7 & 4.903 \\
\hline 88.9 & 63.5 & 70.61 & 17.02 & 137.8 & 4.196 \\
\hline 88.9 & 76.2 & 53.34 & 11.94 & 137.4 & 3.751 \\
\hline 88.9 & 88.9 & 42.93 & 8.382 & 137.5 & 3.438 \\
\hline 88.9 & 101.6 & 36.07 & 6.096 & 137.3 & 3.23 \\
\hline 88.9 & 114.3 & 31.5 & 4.318 & 137 & 3.084 \\
\hline 88.9 & 127 & 27.94 & 3.048 & 137.9 & 2.966 \\
\hline
\end{tabular}




\section{Submit or recommend next manuscript to SCIRP and we will provide best service for you:}

Accepting pre-submission inquiries through Email, Facebook, LinkedIn, Twitter, etc.

A wide selection of journals (inclusive of 9 subjects, more than 200 journals)

Providing 24-hour high-quality service

User-friendly online submission system

Fair and swift peer-review system

Efficient typesetting and proofreading procedure

Display of the result of downloads and visits, as well as the number of cited articles

Maximum dissemination of your research work

Submit your manuscript at: http://papersubmission.scirp.org/ 